\title{
Indocyanine green as a prospective sensitizer for photodynamic therapy of melanomas ${ }^{\star \star}$
}

\author{
Krystyna Urbanska ${ }^{1 凶}$, Bożena Romanowska-Dixon ${ }^{2}$, Zenon Matuszak ${ }^{1,4}$, Janusz \\ Oszajca $^{3}$, Patrycja Nowak-Sliwinska ${ }^{1,3}$ and Grażyna Stochel ${ }^{3}$ \\ ${ }^{1}$ Institute of Molecular Biology and Biotechnology, ${ }^{2}$ Ophthalmology Department, Collegium \\ Medicum, and ${ }^{3}$ Faculty of Chemistry, Jagiellonian University, ${ }^{4}$ Faculty of Physics and Nuclear \\ Techniques, Academy of Mining and Metallurgy, Kraków, Poland
}

Received: 25 September, 2000; revised: 18 March, 2002; accepted: 24 April, 2002

Key words: melanoma, photodynamic therapy, indocyanine green

\begin{abstract}
Spectroscopic, photochemical and biological properties of indocyanine green (ICG) are presented. Light over $800 \mathrm{~nm}$ is effectively absorbed by ICG. This property as well as photochemical behaviour of ICG make it a very suitable dye for photodynamic treatment of melanoma cells. Cytotoxicity of ICG itself and the effect of photodynamic therapy (PDT) were evaluated by following the growth of human (SKMEL 188) and mouse (S91) melanoma cells. The surviving fraction of the cells irradiated $\left(\lambda_{\mathrm{ex}}=\mathbf{8 3 0}\right.$ $\mathrm{nm}$ ) vs non-irradiated, treated with the same dose of ICG, is significantly decreased (5to 10 -fold). These results show that ICG is a very promising dye for photodynamic therapy of melanomas.
\end{abstract}

The use of photosensitizers coupled with light irradiation is a widely studied method (photodynamic therapy, PDT) in the treatment of a great variety of malignant tumours (Baumler et al., 1999). Poor therapeutic results were reported for pigmented human melanoma (Dougherty, 1987; Zhou, 1992) and for experimental melanoma (Kukielczak et al., 1995). This might be explained by a high content of melanin, which can act as a screen for white light (Chedekel, 1995). A good photosensitizer for melanomas must selectively photodamage the tumour tissue when irradiated with visible or preferably near infrared

\footnotetext{
“Preliminary report was presented at the 5th Symposium “Free Radicals in Biology and Medicine”, Łódź, Poland, 7-10 June, 2000.

This paper was supported by the State Committee for Scientific Research (KBN, Poland) grants 4 P05C 01108 and 3 T09A 11515.

${ }^{凶}$ To whom correspondence should be addressed: Krystyna Urbanska, Institute of Molecular Biology and Biotechnology, Jagiellonian University, Gronostajowa 7, 30-387 Kraków, Poland; fax: (48 12) 252 6902; e-mail: Urbanska@mol.uj.edu.pl
}

Abbreviations: ICG, indocyanine green; $\mathrm{NaCl} / \mathrm{P}_{\mathrm{i}}$ buffer; PDT, photodynamic therapy. 
light. In this contribution we describe a new potential photosensitizer for PDT, indocyanine green (ICG).

ICG, commonly used as an angiographic agent, has a very interesting photochemical property: it has a strong absorption between $700-800 \mathrm{~nm}$ (Baumler et al., 1999). It is known that melanins practically do not absorb in this area (Chedekel, 1995). On the other hand, the near infrared light is characterized by a deep penetration into tissues (Wilson et al., 1985).

Considering these facts, it was tempting to examine the influence of the ICG-mediated PDT of human (SKMEL 188) and mouse (S91) melanoma cells in vitro. Some photochemical properties of the compound were also tested to explain the mechanism of ICG action.

\section{MATERIALS AND METHODS}

Chemicals. ICG obtained from Sigma was used for spectrophotometric measurements and ICG-Pulsion (PULSION Verwaltungs GmbH \& Co., Munich, Germany) was used for bioassays.

Instrumental. Absorption was measured using the Hewlett Packard 8453 diode array spectrophotometer.

Photobleaching experiments were carried out in a special $1 \mathrm{~cm}$ black quartz cell with a transparent hole (to eliminate diffusion artifacts), connected to a diode laser equipped with a fibre optical connector. The laser emission of $830 \mathrm{~nm}$ was used.

\section{Bioassays}

Cytotoxicity assay. To check the cytotoxicity of ICG on human melanoma cells (SKMEL 188) and mouse melanoma cells (S91), the cells were incubated for $4 \mathrm{~h}$ in $\mathrm{NaCl} / \mathrm{P}_{\mathrm{i}}$ buffer containing different concentrations of the dye $(10-250 \mu \mathrm{M})$. Thereafter the cells were maintained in the culture medium: F10 with 10\% serum (SKMEL) and
RPMI with 5\% serum (S91) for $48 \mathrm{~h}$. The cytotoxicity in the dark was monitored by counting the number of untreated and ICG treated cells.

Photodynamic effect measurements. To evaluate the influence of the ICG-based PDT on cell growth, the investigated cells were irradiated using a diode laser (MC LASER, therapy laser processor PMC-018, Katowice, Poland). All irradiations were performed at $\lambda_{\mathrm{ex}}=$ $830 \mathrm{~nm}$ and at a fluence rate of 100 or 200 $\mathrm{mW} / \mathrm{cm}^{2}$ with the doses from 30 to $100 \mathrm{~J} / \mathrm{cm}^{2}$ in the presence of the photosensitizer $(100 \mu \mathrm{M})$. After irradiation the cells were incubated in the culture medium for $48 \mathrm{~h}$. Surviving cells were monitored by counting the number of untreated and PDT treated cells.

\section{RESULTS AND DISCUSSION}

Figure 1 presents the chemical structure of indocyanine green (ICG). The ICG optical spectrum consists of two main peaks, at 778 $\mathrm{nm}$ and at $708 \mathrm{~nm}$ (Fig. 2). The shape of the absorption curve fits well to the Gaussian curves peaked at the absorption maxima (not shown). The absorption maxima refer to two forms of the dye, the monomeric form $(778 \mathrm{~nm})$ with a molar absorption coefficient of $10800 \mathrm{M}^{-1} \mathrm{~cm}^{-1}$ and an oligomeric form $(708 \mathrm{~nm})$. It seems that the tetrameric form is dominating (Zhou et al., 1994). The equilibrium between the forms depends on several factors such as dye concentration (Fig. 2), nature of the solvent, ionic strength, $\mathrm{pH}$ and temperature (not shown). With increasing concentration of ICG, the content of monomeric form decreases and the absorption is shifted towards shorter wavelengths. This fact reflects an increase in the amount of oligomeric forms in solution. Also a rise in ionic strength may change the ratio between monomers and n-mers in the system, increasing the aggregation rate (Landsman et al., 1976). Considering that ICG itself is practically insoluble in phosphate buffer, we dis- 


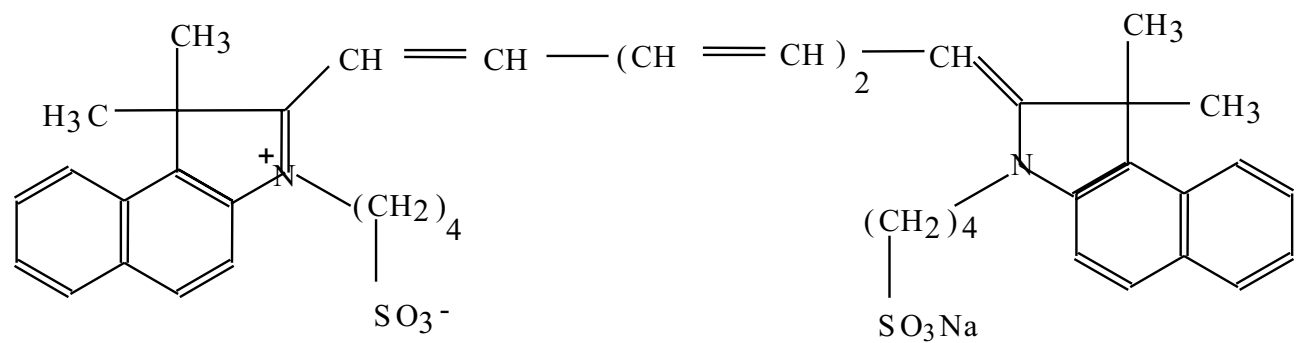

Figure 1. Chemical structure of indocyanine green.

solved the dye first in water and then added the prepared ICG solution to $\mathrm{NaCl} / \mathrm{P}_{\mathrm{i}}$ buffer. The n-mer forms of ICG were dominant in the final solution (Fig. 3).
ICG solutions are not stable (Landsman et al., 1976; Zhou et al., 1994). After a few days a new peak with a maximum near $900 \mathrm{~nm}$ appears (inset in Fig. 2, curve D), probably due
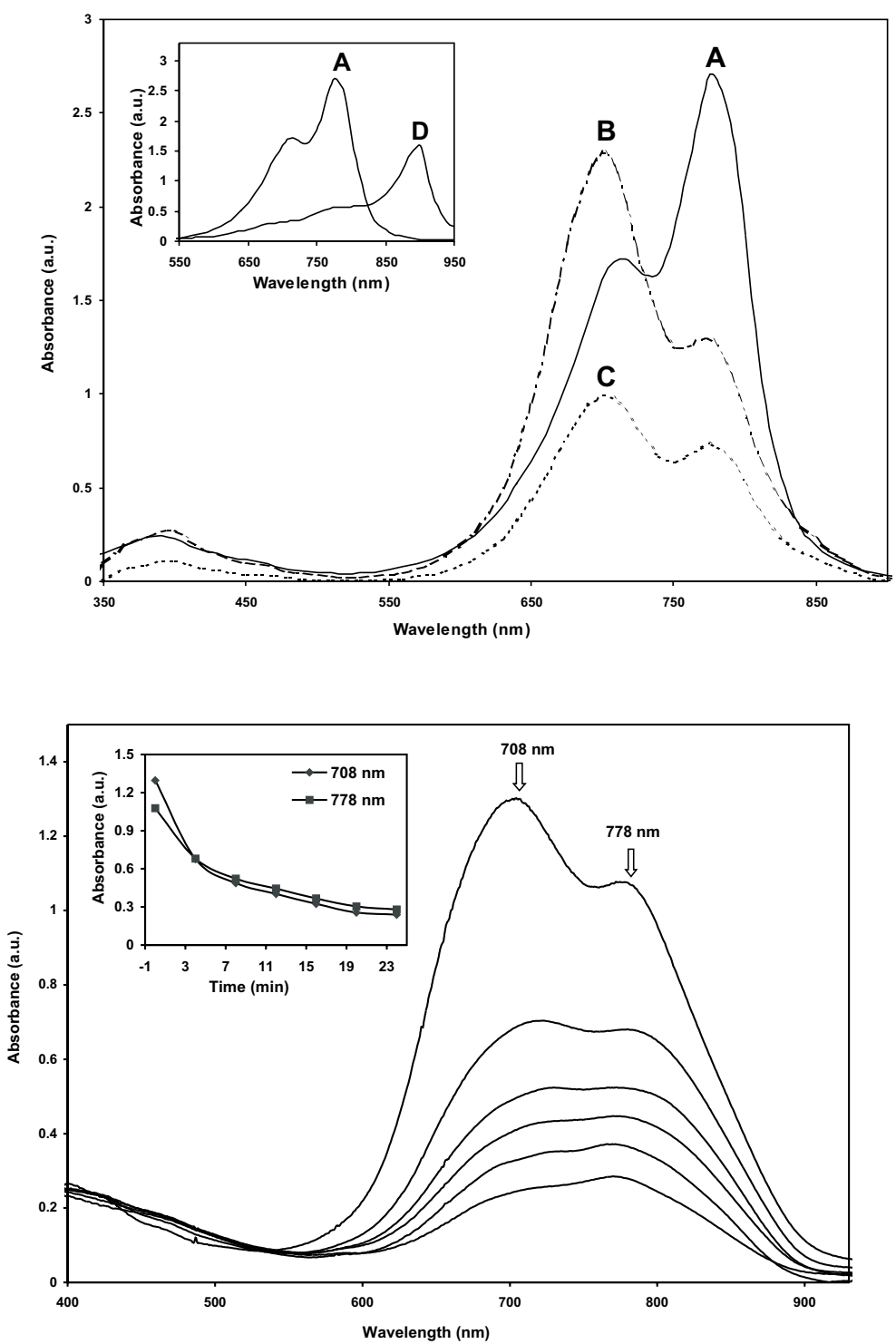

Figure 2. Absorption properties of freshly prepared ICG in water at indicated concentrations.

A, $2.5 \times 10^{-5} \mathrm{M}(1 \mathrm{~cm}$ cuvette $)$; $\mathrm{B}, 2.5 \times 10^{-4} \mathrm{M}(0.1 \mathrm{~cm}$ cuvette); C, $1.25 \times 10^{-4} \mathrm{M}(0.1$ cm cuvette). Inset: Freshly prepared (A) and two-day-old (D) solution of ICG $\left(2.5 \times 10^{-5} \mathrm{M}\right.$ in $1 \mathrm{~cm}$ cuvette).
Figure 3. Changes in the absorption spectrum of ICG $\left(2.5 \times 10^{-5} \mathrm{M}\right)$ in $\mathrm{NaCl} / \mathrm{P}_{\mathrm{i}}$ buffer irradiated at $830 \mathrm{~nm}$.

Inset: Time-dependence of maxima during irradiation, at 778 $\mathrm{nm}(\square)$ and at $708 \mathrm{~nm}(\diamond)$. 


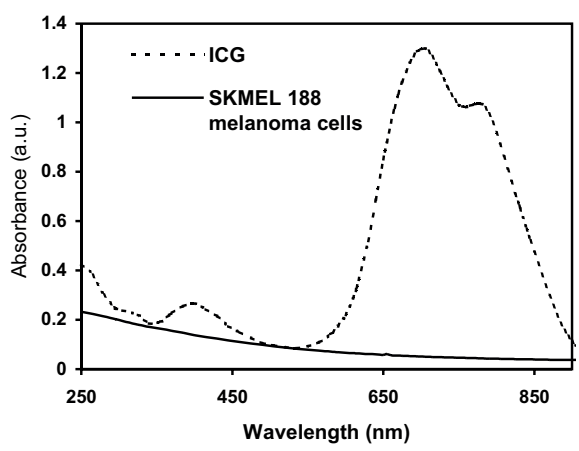

Figure 4. Absorption spectra of SKMEL 188 melanoma cells ( $3 \times 10^{6}$ cells in $1 \mathrm{~cm}$ cuvette) and ICG $\left(2.5 \times 10^{-5} \mathrm{M}\right.$ in $1 \mathrm{~cm}$ cuvette $)$.

SKMEL cells are a little pigmented in the spectral region but beyond ICG absorption.

to degradation and further polymerization. This is connected with the formation of so called J-aggregate (Weigand et al., 1997). Degradation depends on many factors like the degree of aggregation, illumination, kind of solvent and oxygen concentration (Zhou et al., 1994).

We observed photobleaching as early as after 3 min of irradiation under conditions comparable to those used in the PDT assay (Fig. 3). The decrease in intensity was similar for both peaks of absorption. After 25 min the absorption was about 4 times lower (inset in Fig. 3).

ICG essentially absorbs in the near infrared part of the spectrum, and this fact is important for melanoma treatment, because melanins practically do not absorb in this wavelength area (Fig. 4).

ICG-based PDT is presented in Fig. 5. The photosensitizing efficiency of ICG was very high for melanoma cells. The surviving fraction of the irradiated cells decreased more than 10-fold (for $100 \mathrm{~J} / \mathrm{cm}^{2}$ with the fluence rate of $200 \mathrm{~mW} / \mathrm{cm}^{2}$ ) compared with nonirradiated cells. Dark toxicity of ICG on SKMEL 188 and S91 melanoma cells was also investigated. At the tested concentrations of the dye survival of the cells was the same.

Near infrared absorbing compounds are ideal for treatment of melanomas because light in this range is not absorbed by

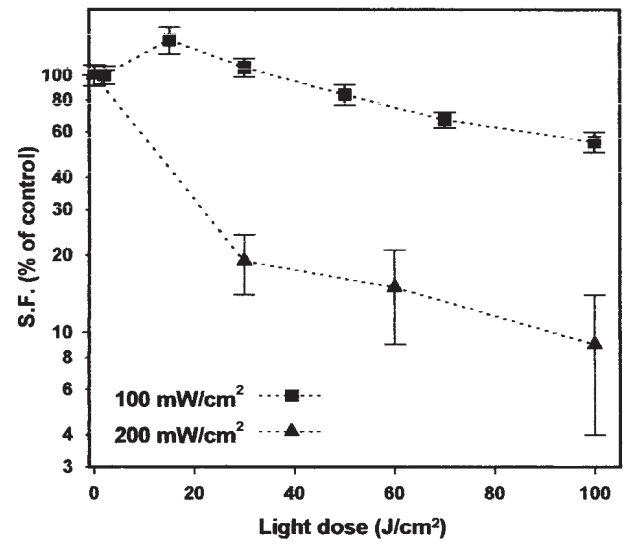

Figure 5. Effect of photodynamic treatment with ICG as sensitizer on the survival of SKMEL 188 cells.

Cells were treated with ICG $(100 \mu \mathrm{M})$, illuminated with indicated fluence $\left(\mathrm{mW} / \mathrm{cm}^{2}\right)$ and further incubated in growth medium in the dark for $48 \mathrm{~h}$.

melanins. Additionally, increased depth of penetration due to longer wavelength enhances treatment effectiveness. The clinically approved dye indocyanine green is a promising photosensitizer in the light of our in vitro data, but needs further investigation under in vivo conditions.

\section{R E F E R E N C E S}

Baumler W, Abels C, Karrer S, Weiss T, Messmann H, Landthaler M, Szeimies RM. (1999) Photo-oxidative killing of human colonic cancer cells using indocyanine green and infrared light. Br J Cancer; 80: 360-3.

Chedekel, MR. (1995) Photophysics and photochemistry of melanin. In Melanin: its role in human photoprotection. Zeise L, Chedekel MR, Fitzpatrick TB. eds, pp. 11-21. Valdenmar Publ Co, Overland Park, KS.

Dougherty TJ. (1987) Photosensitizers: therapy and detection of malignant tumors. Photochem Photobiol.; 45: 879-89.

Kukielczak B, Cieszka KA, Matuszak ZT, Subczynski WK. (1995) Experimental photodynamic therapy of Bomirski hamster melanoma using merocyanine 540 and visible light. Curr Topics Biophys.; 19: 66-70. 
Landsman MLJ, Kwant G, Mook GA, Zijstra WG. (1976) Light-absorbing properties, stability, and spectral stabilization of indocyanine green. J Appl Physiol.; 4: 575-83.

Weigand R, Rotermund F, Penzkofer A. (1997) Aggregation dependent absorption reduction of indocyanine green. $J$ Phys Chem A; 101: $7729-34$.

Wilson BC, Jeeves WP, Lowe DM. (1985) In vivo and post mortem measurements of the atten- uation spectra of light in mammalian tissues. Photochem Photobiol.; 42: 153-62.

Zhou C. (1992) Mechanisms of tumour necrosis induced by photodynamic therapy. J Photochem Photobiol B; 3: 299-318.

Zhou JF, Chin MP, Schafer SA. (1994) Aggregation and degradation of indocyanine green. SPIE Proc.; 2128: 495-505. 